\title{
Effects of Self-Monitoring on Examination Phobia of Computer Science Students in Nigerian Colleges of Education
}

\author{
Joachim Chinweike Omeje ${ }^{1}$, C. I. Oparanozie ${ }^{1}$, Mkpoikanke Sunday Otu $^{1 *}$, \\ Victoria Ogwa Adikwu ${ }^{2}$, Nneka Charity Nwosu ${ }^{1}$, Chinweuba Ngozi Hope ${ }^{1}$, \\ Petronilla Ngozi Omeje ${ }^{1}$, Eberechukwu Francisca Chigbu ${ }^{1}$, Victor Sunday \\ Ezema $^{1}$, Doris Chika Egeonu ${ }^{1}$, Rev. Sr. Ibe Kizito Chinedu ${ }^{1}$ \\ and Ozoemena Lilian Chijioke ${ }^{1}$ \\ ${ }^{1}$ Department of Educational Foundations, Faculty of Education, University of \\ Nigeria, Nsukka, P.M.B. 410001, Nsukka, Nigeria \\ ${ }^{2}$ Department of Counselling and Educational Psychology, University of Abuja, \\ Abuja, Nigeria \\ mkpoikanke.otu@unn.edu.ng
}

\begin{abstract}
The study focused on effects of self-monitoring on examination phobia of computer science students in Nigerian Colleges of Education. Based on the purpose of the study two researchers questions were formulated and one hypothesis tested at 0.05 level of significance guided the study. True experimental researchers design was adopted for the study. Voluntary sampling technique was used to compose a sample of 60 computer science students used for the study. The instruments for data collection were Student Examination Phobic Traits Identification Questionnaire (SEPTIQ) and Examination Phobia Manifestation Scale (EPMS) developed by the researchers. The internal consistency reliability coefficient was determined for both the Students' Examination Phobic Traits Identification Questionnaire (SEPTIQ) and the Examination Phobic Manifestation Scale (EPMS) using cronbach alpha and reliability estimates of 0.73 and 0.95 respectively were got. The data collected were analyzed using descriptive statistics of mean and standard deviation while the hypothesis was tested at $P<0.05$ level of significance using ANCOVA. Results showed that computer science students exposed to treatments using self-monitoring had significant reduction on their examination phobia manifestation than those not exposed. Gender is not a significant factor influencing the manifestation of examination phobia. Based on the above findings, discussions were made. The educational counselling implications of the findings were highlighted. Subsequently, conclusion and recommendation were proffered.
\end{abstract}

Keywords: Self-monitoring, examination phobia, computer science students, Nigerian Colleges Education

\section{Introduction}

One of the major problems facing the Nigerian secondary school educational system today is that of examination malpractice which has its origin from examination phobia (Sylvia, 2005). In Imo State many students that have examination phobia normally nurse fear of failure to attain academic success or that they will not be able to attain the standard of academic excellence expected of them as brilliant or intelligent students (Njoku, 2000). The author further noted that this situation cuts across male and female students. Both male and female students manifest ailments such as abdominal pains, vomiting,

Received (February 4, 2018), Review Result (April 25, 2018), Accepted (April 29, 2018) 
headaches, dizziness, heart pounding or racing, unsteadiness, feelings of choking, hands trembling, and fear of losing control, difficult breathing and difficulty in remembering studied materials which have no apparent medical basis (Njoku, 2000).

In the educational process, although the role of examination is of great importance, some students suffer from fear of examination. More than 50 percent of students suffer from examination phobia. It does not matter whether the student is intelligent or not. They all are worried about forgetting while appearing in an examination. The author further stated that examination phobia is a major problem for a large number of students. For them examination is something which is almost inevitable. (Davis, 2016).

The concept phobia has been defined variously by authors. Hornby (2010) stated that it is a strong unreasonable fear of something or hatred for a particular thing. Phobia is used for sudden and violent fear, fright, panic for something, person or situation. In its verbal form, it carries reasonable sense, to put to flight, to terrify, to feel, to be frightened, to be afraid, and to be apprehensive. In each of these minces, a picture of real or imagined, external or internal objectives of fear is being portrayed. (Oluwatelure, 2016).

The fear may be imagined. Andrew (2003) stated that it is a persistent, irrational fear of an object, event, activity or situation called a phobic stimulus resulting in a compelling desire to avoid it. The presence or anticipation of the phobic stimulus triggered anxiety or a panic attack. Although the person acknowledges the fear to be irrational, the phobic stimulus is either avoided or endured with dread. The phobia that leads to clinical significant distress or impairment in social, occupational or other important areas or functioning may be diagnosed as a mental disorder-either a specific phobia or a social phobia.

A phobia is an irrational, intense persistent fear and anxiety of certain situation, objects and activities. Phobias are of different types. Common types of phobias include Anthrophobia (fear of people being in a company), Ergophobia (fear of work or functioning), and Hydrophobia (fear of water), decidophobia is the fear of making decisions. An individual suffering from this kind cannot take any kind of decision in difficult situations (Khartoum \& Praveen 2011).

Furthermore, most phobias (clinical) are classified into three categories and, according to the diagnostic and statistical manual of mental disorders, (fourth edition) (DSM-IV), such phobias are considered to be sub-type of anxiety disorder. The three categories are: (i) Social phobia (fear of other people or social situations such as performance anxiety or fears of embarrassment by scrutiny of others). Social phobias may be further subdivided into generalized social phobia (also known as social anxiety disorder or simply social anxiety) specific social phobia (in which anxiety is triggered only in specific situations. (ii) Specific phobias (fear of a single specific panic trigger such as spiders, snakes, dogs, water, heights, flying and catching a specific illness among others). (iii) Agoraphobia (a generalized fear of leaving home or a small familiar "safe" area and of possible panic that might follow).

Examination phobia is a self damaging factor which negatively affects the students and their performances. The student is unable to give his maximum productivity and the end result would be critical (Ruwam, 2008). The author further stated that a person who demonstrates typically low rates of examination confidence in partaking with others such as classmates on a given examination has examination phobia. As noted by (Vahey in Oparanozie, 2016), examination phobia is a type of fear of classroom activities. Examination fear is viewed as the tendency to avoid evaluation of classroom activities and a failure to participate appropriately in an academic situation. The author further stated that examination phobic behaviour is considered deficient and in school, a child who is manifesting high examination fear is educationally rejected, neglected and is unaccepted by the classmates. The students who experience phobia are also characterized by acute anxiety, apprehension, tension or uneasiness, willful domination, depressions, despair, sadness and an unrealistic self-image. 
Examination phobia, an avoidance problem behaviour have serious negative implication for students experiencing it. It could mar or rather jeopardize students' future, thereby creating nuisance such as examination malpractice among gender variables. Like many other anxiety disorders, epidemiological investigations have consistently revealed a greater proportion of females than males with specific phobia (Oparanozie, 2016). She further stated that females manifest examination phobia more than their male counterparts and that as a means of escaping from such situations both gender resorts to examination malpractices.

Since examination phobia has negative effects on students, there is the need for appropriate long term or permanent solution to the devastating effect of examination phobia on the personality of students involved in it. It is indisputable that some of the students who suffer from examination phobia end up not performing well either in internal or external examination. This ugly development should not be allowed to continue hence the need for utilizing appropriate behavioural techniques in addressing the problem.

Such techniques as self monitoring has been seen by scholars such as Agulana and Nkwocha (1999); Ogbobor and Egbule (2006), Ede (2007), among others as being effective in changing behaviours such as drug abuse and bullying. Whether, the use of self monitoring could equally be used to modify phobia among secondary school students in Imo State is yet to be empirically ascertained. In view of the above the researchers hopes to find out the effect of self-monitoring on examination phobia reduction.

Self-monitoring is a technique that deals with the phenomena of expressive controls. Human beings generally differ in substantial ways in their abilities and desires to engage in expressive control (Ajzen in Oparanozie, 2016). People concerned with their expressive self-presentation tend to closely monitor themselves in order to ensure appropriate or desired public appearances. People who closely monitor themselves are categorized as high self-monitors and often behave in a manner that is highly responsive to social cues and their situational context.

Measurement of one's own behaviour is called self-monitoring, and it can be an effective tool for behaviour change. Self-monitoring often works especially well with impulsive habits. To really work, self-monitoring must be done honestly without cheating. It forces a person to think about every occurrence of behaviour and as well draws attention to the consequences of behavior irrespective of gender (Richmond, 2011). In the context, self-monitoring is concerned with careful observation and measurement of one's behaviour. It also involves the recording and analyzing of the target behaviour which when honestly done brings about change in behaviour and the recipient appreciates the importance of stimulus control.

Gender also refers to the cultural differences expected by society/culture of men and women according to their sex. Furthermore, in the past people tend to have clear ideas about what was appropriate to each sex and anyone behaving differently was regarded as deviant. Today, we accept a lot more diversity and see gender as a continuum (i.e., Scale) rather than two categories (Shaywitz in Oparanozie, 2016). Operationally gender can be seen as a behavioural, social and cultural attributes associated with sex. Gender as a variable is an important factor in looking at self-monitoring.

A number of factors accounted for the choice of self-monitoring in the present study. Among them is that phobia especially examination phobia is a behavioural problem; and it seems most appropriate that behaviour modification techniques be employed in taking care of them. Therefore, there is need to explore through empirical study, the use of selfmonitoring on examination phobia of computer science students in Nigeria.

\subsection{Statement of the Problem}

It has become increasingly apparent in recent years that students develop fear and anxiety about the uncertainty of the outcome of their performances and consequently 
develop phobia for examination. This calls for immediate attention of psychologists, counsellors and teachers if students are to function creditably well in their academic work as well as develop, sustain and maintain desirable behaviour before and during examination. What this implies is that there is the need for appropriate behaviour modification so as to make students develop positive behaviour toward examination.

The use of behaviour modification techniques such as self-monitoring has been found to be effective in managing drug abuse and bullying among students. Whether selfmonitoring will be effective in developing self confidence among students during examination needs to be empirically established. The question which this study addresses is: what is the effect of self-monitoring on examination phobia of computer science students Nigerian Colleges of Education?

\subsection{Purpose of the Study}

The main purpose of the study was to determine the effects of self-monitoring on examination phobia of computer science students in Nigeria.

Specifically, the study sought to find out:

1. Effect of self-monitoring on examination phobia of computer science students in Nigerian colleges of education.

2. The influence of gender on computer science students' manifestation of examination phobia when exposed to self-monitoring.

\subsection{Research Questions}

The following questions guided the study:

1. What is the effect of self-monitoring on examination phobia of computer science students?

2. What is the influence of gender on students' manifestation of examination phobia when exposed to self-monitoring?

\subsection{Hypothesis}

The following null was hypothesis was formulated to guide the study and was tested at 0.05 level of significance: There is no significant difference between the pre test and post test mean score on examination phobia of secondary school students due to selfmonitoring.

\section{Methods}

\subsection{Design}

The researchers design is true experimental researchers design. In using the true experimental design, the sample groups must be assigned randomly and there must be a viable control group, only one variable can be manipulated and tested and finally the tested subjects must be randomly assigned to either control or experimental groups.

The justification for the use of this design is because the results of a true experimental design can be statistically analyzed and so there can be little argument about the results. It is also much easier for other researchers to replicate the experiment and validate the results.

\subsection{Area of the Study}

The study was carried out in southeast Nigeria. 


\subsection{Population of the Study}

The population of the study consists of all computer science students in south-east Nigeria, estimated at 3515 .

\subsection{Sample and Sampling Techniques}

The sample for the study was 60 computer science students from southeast Nigeria, selected through voluntary sampling technique. The eligible students were drawn using Students Examination Phobic Trait Identification Questionnaire (SEPTIQ). A bench mark of 2.50 was used to determine one with or without examination phobia. This gave a composed sample of 60 students that were used for both the experimental and the control. Random sampling was used to assign 30 students to experimental group for selfmonitoring and 30 students to the control for the same group. School A was for experimental on self-monitoring, while school B is the control group.

\subsection{Instrument for Data Collection}

The study made use of two instruments viz Student Examination Phobic Trait Identification Questionnaire (SEPTIQ) and Examination Phobia Manifestation Scale (EMPS). The SEPTIQ was administered on SS 2 students of the sampled school to help in identifying the students that manifest examination phobia. It has a 4 point rating response of Always, Often, Sometimes and Never. It consisted of 10 items and assigned weight of 4.3.2 and 1 point respectively. The students were required to indicate their response on 4 point scale showing their degree of agreement or otherwise to each statement.

The second instrument for the study was Examination Phobia Manifestation Scale (EPMS) developed by the researchers. It consisted of 12 items generated directly from the review of related literature carried out by the researchers. The questionnaire items were used for both the pretest and post-test on both treatment and control groups. However, the items of the instrument were reshuffled during the post-test to make it look different from the pre-test. This helped to prevent memory effect of pre-test.

The EPMS was divided into two parts 1 and 2. The part I is on the personal data of the subjects such as gender, class and school. The part 2 is the questionnaire section discussing examination phobia manifestations among secondary school students. The EPMS is a 4 point rating scale of Always (A), Often (O), Sometimes (S) and Never (N). It has assigned weight of 4.3.2 and 1 point respectively. The students were required to indicate response on 4-point scale showing their degree of agreement or otherwise to each of the statements.

The face validation of SEPTIQ and EPMS were ascertained by the researchers. This was done by giving initial draft to three experts from Faculty of Education University of Nigeria, Nsukka. In order to determine the reliability of the instruments, the validated instrument for Students Examination Phobic Trait Identification (SEPTIQ) and Examination Phobia Manifestation Scale (EPMS) were subjected to reliability testing on a representative of 30 SS II students from Owerri North Local Government Area which was outside the Owerri Municipal Council of Imo State. The reliability testing enabled the researchers to generate the relevant data for measuring the internal consistency of the instrument.

The relevant reliability estimates were established for the instruments (SEPTIQ) and (EPMS). This was done using Cronbach alpha method to measure the internal consistency coefficient. The values obtained were 0.73 and 0.95 for the (SEPTIQ) and (EPMS) respectively. Cronbach alpha was used based on the ground that the items have no right or wrong answers and they were not dichotomously scored. 


\subsection{Experimental Procedure}

The experimental procedure was carried out in three phases viz: Pre-treatment Phase, Treatment Phase and Post-treatment Phase.

This study being an experimental researchers involved a realistic manipulation of the independent variables (Self-monitoring) by the researchers under a carefully controlled condition which was very necessary in a field experiment. This was made possible by the researchers controlling some extraneous variable such as Hawthorn effect, subject's variability, pre-test, post-test effect, instability of instrument among others variable which may otherwise have effects on the variables under study.

\subsection{Method of Data Collection}

On commencement of the treatment, the researchers visited the sampled schools and explained the purpose of the study to the school head (principal). The researchers handed over copies of the instrument to each of the researchers assistants for immediate pretesting of the student participants. The researchers went back later in the day and collected the filled questionnaire from various researchers assistants after students responses. This ensured a high return rate after the pretest. At the end of the treatment the researchers distributed the same number of copies of the questionnaire with renumbered items to the researchers assistants who administered them to the participants as post-test. The researchers collected them back later in the day so as to ensure a high return rate.

\subsection{Method of Data Analysis}

The data collected by administering the instrument were analyzed based on each researchers question and hypothesis. Descriptive statistics such as mean and standard deviation were used in answering the questions. Analysis of covariance (ANCOVA) was used to test the hypothesis at $\mathrm{P}<0.05$ level of significance. ANCOVA was also used to determine if there would be any significant difference in the mean score of the groups.

\section{Results}

\subsection{Tables 1. Mean and standard deviation of participants' scores on the effect of self-monitoring on examination phobia}

\begin{tabular}{|c|c|c|c|c|c|c|}
\hline \multirow[t]{2}{*}{ Group } & \multicolumn{4}{|c|}{ Pre-test } & Post-test & Mean Gain \\
\hline & $\mathbf{N}$ & Mean & SD & Mean & SD & \\
\hline Experimental & 30 & 30.13 & 12.27 & 28.73 & 12.50 & 1.40 \\
\hline Control & 30 & 27.50 & 6.59 & 27.6 & 6.60 & 0.10 \\
\hline
\end{tabular}

The analysis of data in table 1 shows the pre-test and post-test mean scores of both the experimental group and the control group. It reveals that the pre-test means score of the experimental group is 30.13 with a standard deviation of 12.27 and a post-test mean score of 28.73 with a standard deviation of 12.50 . Similarly, the control group had a pre-test mean score of 27.50 with a standard deviation of 6.59 and a post-test mean score of 27.66 with a standard deviation of 6.60. This analysis indicates that there was a decrease in the post-test mean score of the experimental group but an increase in the post-test mean score of the control group. This may be as a result of the treatment. 
3.2. Tables 2. Mean and standard deviation of participants' scores on influence of gender on students' examination phobia manifestation when exposed to selfmonitoring

\begin{tabular}{llll}
\hline Experimental group & N & Mean & SD \\
\hline Self-monitoring & 15 & 17.4667 & 2.06559 \\
Male & 15 & 40.0000 & 6.91789 \\
Female & & & \\
Control & 15 & 41.8667 & 2.16685 \\
Male & 15 & 28.5333 & 8.21033 \\
Female & & & \\
\hline
\end{tabular}

Data in Table 2 above shows that males in self-monitoring group had a mean score of 17,47 with standard deviation of 2.07 while males in the control group had a mean score of 41.87 and standard deviation of 2.17. The females in self-monitoring group had a mean score of 40.00 with standard deviation of 6.92 while females in the control group had a mean score of 28.53 with standard deviation of 8.21. The above result shows that the males and females in the treatment group benefitted immensely from the treatment compared to the males and females in the control group.

\subsection{Tables 1 Analysis of Covariance of the effect of self-monitoring on examination phobia by treatment and gender}

\begin{tabular}{llllll}
\hline Source & Type III sum of Squares & df & Mean Square & F & Sig. \\
\hline Corrected Model & $3980.835 \mathrm{a}$ & 4 & 995.209 & 29.736 & .000 \\
Intercept & 920.133 & 1 & 920.133 & 27.493 & .000 \\
Pre-test & 152.302 & 1 & 152.302 & 4.551 & .037 \\
Group & 1.566 & 1 & 1.566 & .047 & .830 \\
Gender & 1527.696 & 1 & 1527.696 & 45.646 & .000 \\
Group * gender & 1660.179 & 1 & 1660.179 & 49.604 & .000 \\
Error & 1840.765 & 55 & 33.468 & & \\
Total & 53536.000 & 60 & & & \\
Corrected Total & 5821.600 & 59 & & & \\
\hline
\end{tabular}

Table 3 shows that the probability associated with the calculated value of $F(.047)$ for the effect of self-monitoring on examination phobia of students is .830 . Since the probability value is greater than 0.05 level of significance $(\mathrm{P}>.05)$, the null hypothesis was accepted. Hence, there is no significant difference between the pre-test and post-test mean scores of students due to self-monitoring effect on management of examination phobia.

\section{Discussion}

The findings of this study were discussed in line with the researchers' questions and hypothesis raised in the study. The result of the study shows differences in the pre-test results of the treatment and control groups. These differences in the pre-test results provided basis on which it could reasonable be assumed that both the treatment and control groups had an equivalent entry examination phobia manifestation at the commencement of the treatment. The overall result indicates that student exposed to treatment using self-monitoring had significant improvement in terms of reduction on the manifestation of examination phobia than those who were not exposed to treatment 
(control group). In other words, the students adopted a more rational behaviour pattern after being exposed to the treatment (self-monitoring).

The Analysis of Covariance (ANCOVA) as presented in Table 3 revealed that the level of significance was .830 and was higher than the 0.05 being the level of significance at which the hypothesis was tested. The null hypothesis II was therefore accepted. Hence, there was no significant difference between the pre-test and post-test mean scores of students due to self-monitoring effect on examination phobia.

The present finding is in agreement with the result of Helton, Workman and Watson in Chinweuba (2011) who investigated the effects of self-monitoring procedure on the sustained school work (SS) behaviour and compliance behaviour of 8 middle school pupils aged 10-12 years who have low rate of appropriate work behaviour during tastks periods and a low rate of compliance with adult instruction. The result of the treatment using an adopted Ecological Assessment of Child Problem Behaviour (EACPB) shows that self monitoring resulted in an increased rate of sustained school work which was accompanied by an increase in compliance behaviour. Also, Ugwuegede (2009) carried out a study on the effect of self-monitoring approach in smoking reduction. The study utilized the true experimental pre-test post-test control group design. Using smoking behaviour questionnaire to collect data, the result of the analysis revealed that selfmonitoring was effective in the reduction of smoking.

The findings on the effectiveness of self-monitoring contradict the finding of Leung and Heimberg in Oparanozie, (2016) that investigated the extent of self monitoring of home work compliance and perceptions of control with student - directed learning versus teacher guidance directed learning. Students directed learning involves teaching students to monitor regularly the use of one or more self directed instructional strategies to plan and perform a given task. Learning involves instruction, task-performance and evaluation of students by the teacher. The result indicate high success rate with teacher - guidance directed learning than student directed learning which involves mostly self-monitoring of their activities. It was noted that the presence of an instructor facilitated task performance by computer science students than leaving them to self-monitor themselves.

The result of the study on influence of gender on students' examination phobia manifestation when exposed to self-monitoring shows that males had lower mean posttest scores that their females counterpart. This implies that there is gender difference in the manifestation of examination phobia. This present study contradicts the finding of Rutherford, Quinn and Mathur in Oparanozie (2016) that tested the effect of selfmonitoring and eating-related behaviours with weight loss and found out the gender is not a factor. This finding however is in line with Ugwuegede (2009) who examined the effect of self-monitoring approach in smoking reduction among computer science students in North Central.

\section{Conclusions and Recommendations}

From the study, it is being concluded that when computer science students were subjected to self monitoring treatment there was a reduction in the examination phobic manifestation. The results of this study have some obvious educational and counselling implications.

The study provided an empirical evidence of the effectiveness of self-monitoring in reducing examination phobia of computer science students. The fact that students exposed to this treatment therapy improved on their behaviour implies that there was remarkable reduction in examination phobia manifested by students, the reduction of which they attested to both at pretest and posttest levels. What this implies is that at secondary school levels, student should be provided with detailed information on behaviour modification techniques so as to improve on their healthy life development. 
Consequently, this technique could now be used in Nigerian colleges of education with a high degree of confidence to enhance reduction in manifestation of examination phobia. If this is done, the problem of low academic performance which had been associated with examination phobia among computer science students would have been solved.

The following recommendations have been proffered based on the findings and implications of the study.

1. There is need for college counsellors to undergo some training on behaviour modification based on self-monitoring through workshops, seminars and conferences which the government can assist in organizing.

2. College guidance counsellors should recognize that gender is not a significant factor in the manifestation of examination phobia among students and therefore should not be biased in planning treatment programme for the students in colleges of education.

3. Curriculum planners, educational psychologists, and guidance counsellors should plan a programme of intervention based on the principles of self monitoring techniques for students.

\section{References}

[1] N. J. Njoku, "Gender Differences in the Perception of Guidance and Counselling Programme: A case study in Alvan Ikoku College of Education, Owerri counseling", Spectrum, vol. 3, no. 1, (2000), pp. 5257.

[2] S. Khatoon and F. Parveen. "Examination phobia among secondary Level Students", International Researchers Journal of Arts and Humanities, no. 37, (2007), pp. 129-146.

[3] C. I. Ugwuegede, "Effect of Self-monitoring approach in smoking reduction among secondary school student in North central Nigeria", Ogun Journal of Counselling Studies, vol. 1, (2009).

[4] C. Okereke, "Implementation of Assertive Training and Systematic Desensitization in Reducing Examination Phobia among University students", Faculty of Education, Imo State University, Oweeri, Nigeria. Journal of Education Research and behaviroual sciences, vol. 4, no. 1, (2014), pp. 001-004.

[5] M. Sufiana and S. Gangestad, "Related studies on Examination Phobia among secondary level students", International research Journal of Arts \& Humanities (IRJAH), ISSN: 1016-9342. http://www.google.com, vol. 37, (2000).

[6] M. C. Andrew, "A Dictionary of Psychology”, United States. Oxford University Press, (2003).

[7] J. P. Drowetzky, "Psychology". New York: Books/Cole publishing company, (1997).

[8] R. F. Nickarson, "Child Development - An introduction. Houghton Mifflin Company", Boston, (2002).

[9] V. N. Nwadinobi, "Effects of Cognitive Restructuring and Assertiveness Training on Reduction of Drug Abuse among secondary school adolescents", Ph.D Thesis University of Nigeria Nsukka, (2016).

[10] N. F. Onwuka, "Relative Effectiveness of three Counselling Therapies in Reducing Test Phobia among Polytechnic students", Ph.D.Thesis Nnamdi Azikiwe University Awka., (2016).

[11] C. I. Oparanozie, "Effects of Systematic Desensitization and Self-monitoring on Examination Phobia of Secondary School Students, Owerri Municipal Council, Imo State, Nigeria”, Ph.D Thesis University of Nigeria, Nsukka, (2016).

[12] S. O. Ede, "Fundamentals of Guidance and Counselling". Enugu: Cheston Agency Ltd., (2009).

[13] G. G. Ogbobor and J. E. Egbule, "Troduction to Psychology", Benin: Justice Jeco Press LTD., (2006).

[14] G. G. Agulanna and P. C. Nkwocha, "Behavbiour disorders of Children and Adolescents", Edited R. U. Obinna., G.G. Agulanna and F.J. Nwachukwu, Nuel Centi publishers \& Academic Press Ltd Awka, (1999).

[15] C. E. Larsen, R. Trip and C. R. Johnson, "Methods for procedures related to the electrophysiology of the heart", U.S. Patent 5,529,067, (1995) June 25.

[16] M. Shuttleworth, "http:www//explorable.com/true-experimental-design.retrieved on 13/8/2013".

[17] World Health Organization Gender, Retrieved from www.who.int/topics/gender/en/, (2014).

[18] R. L. Richmond, "A guide to psychology and its practice", San Francisco. www.guideTopyschology.com, (2011). 
International Journal of $u$ - and e- Service, Science and Technology

Vol. 11, No.3 (2018) 